\title{
SIMULASI PROSES PRODUKSI KUE ALI (LEDRAM) PAK BEBEN DI DESA LEMAH DUHUR, TEMPURAN, KABUPATEN KARAWANG
}

\author{
Amelia Nur Fariza ${ }^{1}$, Annisa Indah Pratiwi ${ }^{2}$, Hendri $^{3}$ \\ ${ }^{1,2,3}$ Jurusan Teknik Industri, Fakultas Teknik dan Ilmu Komputer, Universitas Buana Perjuangan \\ Karawang Jl. HS. Ronggowaluyo Telukjambe Timur Karawang, \\ Email: amelia.nur@ubpkarawang.ac.id
}

\begin{abstract}
Ali's cake (ledram) is one of Karawang's specialty foods which is shaped like a donut made from a mixture of rice flour, coconut milk, and brown sugar. The steps for making Ali cake (ledram) start from preparing the ingredients, cooking coconut milk, brown sugar, and granulated sugar. Next is the process of mixing rice flour into the coconut milk and sugar mixture, then proceed with the cake molding process and the frying process. The last stage of making Ali cake (ledram) is the packaging and shipping process. From the results of observations in the field, then an analysis was carried out for making conceptual models and simulations. The simulation of the Ali cake production process (ledram) was carried out using ProModel software. The simulation results show a high rate of cake delivery failure. Next, a repair scenario is made for the system that is already running, namely by adding man power. The simulation results of the improvement system show that there is no delivery failure in the cake delivery process flow. The transfer process of ready-to-pack cakes to ready-to-deliver cakes is smooth, there is no buildup or over capacity.
\end{abstract}

Keyword: Process production; simulation; ProModel

\begin{abstract}
ABSTRAK
Kue Ali (ledram) merupakan salah satu makanan khas Karawang yang berbentuk seperti donat yang terbuat dari campuran tepung beras, santan, dan gula merah. Langkah pembuatan kue Ali (ledram) dimulai dari menyiapkan bahan, memasak air santan, gula merah, dan gula pasir. Selanjutnya dilakukan proses pencampuran tepung beras ke dalam adonan santan dan gula, lalu dilanjutkan dengan proses pencetakan kue dan proses penggorengan. Tahap terakhir dari pembuatan kue Ali (ledram) adalah proses pengemasan dan pengiriman. Dari hasil observasi di lapangan, kemudian dilakukan analisis untuk pembuatan model konseptual dan simulasi. Simulasi proses produksi kue Ali (ledram) dilakukan dengan menggunakan software ProModel. Hasil simulasi menunjukkan tingginya tingkat kegagalan pengiriman kue. Selanjutnya dibuat skenario perbaikan untuk sistem yang sudah berjalan yaitu dengan menambahkan man power. Hasil simulasi dari sistem improvement, terlihat bahwa tidak adanya kegagalan pengiriman pada aliran proses pengiriman kue. Proses transfer kue siap kemas ke kue siap kirim lancar, tidak terjadi penumpukan atau over kapasitas.
\end{abstract}

Kata kunci: proses pembuatan kue Ali (ledram); simulasi; ProModel

\section{PENDAHULUAN}

Kue Ali (ledram) merupakan salah satu makanan tradisional Sunda yang berasal dari Karawang, yang berbentuk mirip dengan donat (Dishub Karawang, 2018). Perbedaan donat dan kue Ali terletak pada bahan dasar, rasa, dan tekstur kuenya. Konon kue ini disebut Ali (ledram) karena merujuk kepada bentuknya yang menyerupai cincin, dimana dalam bahasa Sunda, cincin disebut dengan Ali. Kue berbahan dasar tepung beras yang dicampur dengan gula merah ini, dahulu sering 
dijumpai dalam berbagai acara tradisi yang berlangsung dalam masyarakat Sunda seperti pernikahan, khitanan, tujuh bulanan, ataupun dalam perayaan hari besar keagamaan seperti Idul Fitri.

Salah satu pelaku UMKM yang masih memproduksi kue ini adalah Pak Beben, yang telah mendirikan usaha Kue Ali (ledram) sejak tahun 2000. Usaha Kue Ali (ledram) Pak Beben berlokasi di Dusun Jarakah, Desa Lemah Duhur, Kecamatan Tempuran, Kabupaten Karawang. Usaha kue Ali (ledram) Pak Beben merupakan salah satu usaha kuliner yang masih bertahan di tengah pandemi ini.

Dari hasil observasi di lapangan, diketahui bahwa sistem produksi kue ini masih belum efisien. Hal ini ditunjukkan dengan minimnya jumlah output kue yang bisa terkirim. Hal ini menjadi sumber permasalahan ketika ada pesanan kue dalam jumlah banyak, tidak dapat sepenuhnya dipenuhi. Oleh karena itu, penelitian ini akan menganalisis faktor yang menjadi kendala dalam sistem produksi kue Ali (ledram) tersebut dengan menggunakan pendekatan pemodelan dan simulasi sistem.

\section{METODE PENELITIAN}

\section{Objek Penelitian}

Sistem produksi kue Ali di UKM Kue Ali (ledram) Pak Beben merupakan objek kajian dalam penelitian ini. Langkah-langkah pembuatan kue Ali (ledram) dimulai dengan menyiapkan bahan, memasak air santan, gula merah, dan gula pasir. Selanjutnya dilakukan proses pencampuran tepung beras ke dalam adonan santan dan gula, lalu dilanjutkan dengan proses pencetakan kue dan proses penggorengan. Tahap terakhir dari pembuatan kue Ali (ledram) adalah proses pengemasan dan pengiriman.

\section{Alat yang Digunakan}

Peralatan yang digunakan dalam penelitian ini terbagi menjadi peralatan observasi dan peralatan untuk pengolahan data. Observasi dilakukan untuk mengetahui alur proses pembuatan kue Ali (ledram) di lapangan. Disini digunakan kamera dan alat tulis untuk melakukan dokumentasi dan pencatatan. Selanjutnya data hasil observasi digunakan sebagai inputan untuk memodelkan sistem dan mensimulasikannya. Simulasi sistem produksi kue Ali (ledram) dilakukan dengan menggunakan software ProModel.

\section{Tahapan Penelitian}

Tahapan penelitian dilakukan mengikuti alur seperti pada Gambar 1 berikut.

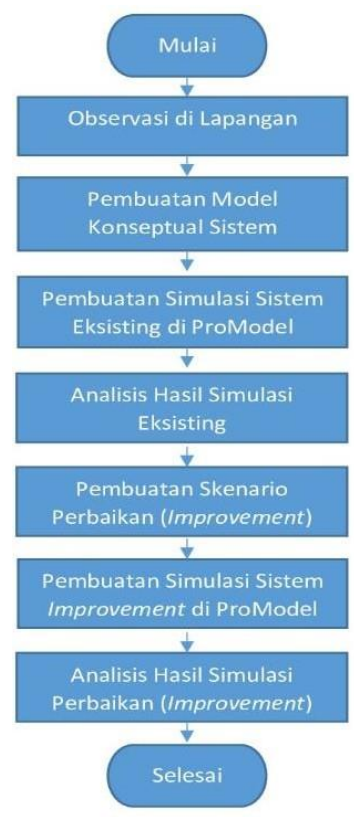

Gambar 1. Tahapan Penelitian 


\section{HASIL DAN PEMBAHASAN}

\section{Model Konseptual}

Model konseptual dilakukan setelah melakukan observasi lapangan untuk mengetahui halhal yang berkaitan dengan sistem produksi kue Ali (ledram) di UKM Pak Beben. Dari hasil observasi diketahui bahwa bahan baku dan man power sangat berpengaruh dalam sistem produksi kue Ali (ledram) ini. Selain itu, di tahap ini juga dilakukan pembuatan peta proses operasi seperti terlihat pada Gambar 2 berikut.

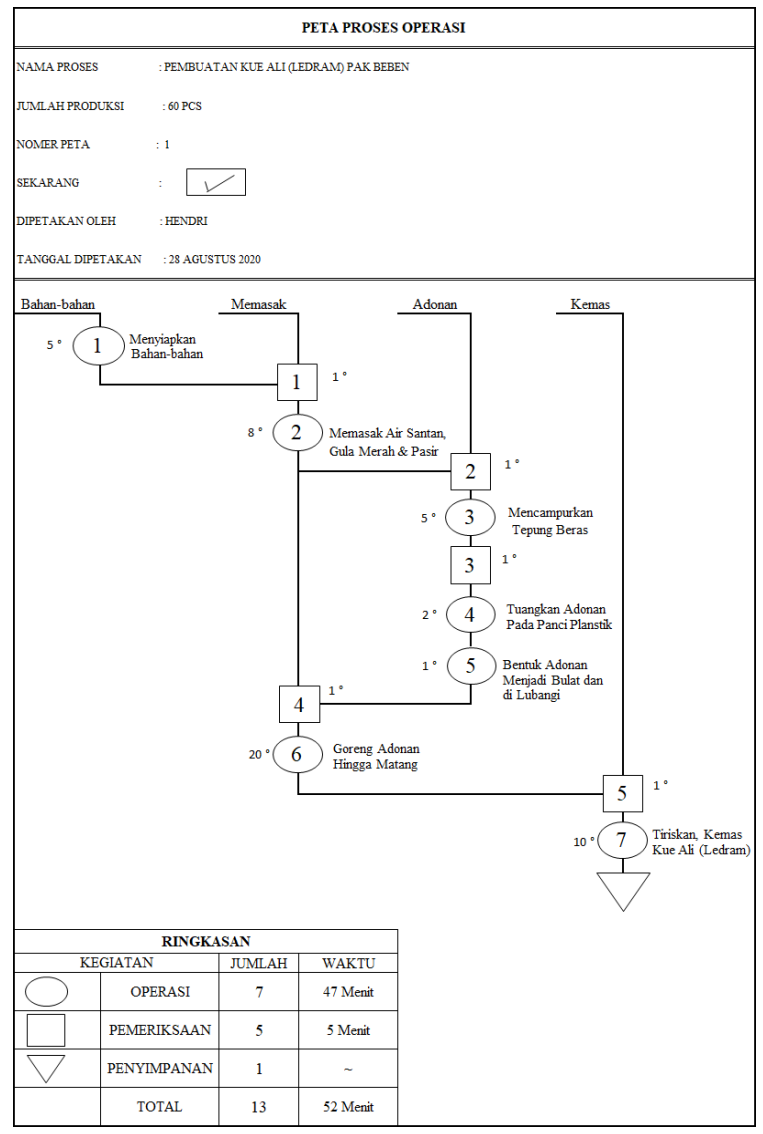

Gambar 2. Peta Proses Operasi Pembuatan Kue Ali (Ledram) di UKM Pak Beben

\section{Pembuatan Simulasi Sistem Eksisting di ProModel}

Pendekatan pemodelan dan simulasi digunakan dalam penelitian ini untuk mencari kendala utama dalam sistem sehingga bisa dilakukan rencana perbaikan tanpa mengacaukan sistem yang telah ada (Siregar, 2107). Simulasi dalam penelitian ini dilakukan dengan menggunakan software ProModel.

\section{a. Stat Fit}

- Buka ProModel, Pilih menu tools dan pilih Stat Fit

- Masukkan data waktu pengiriman kue ali (ledram) 


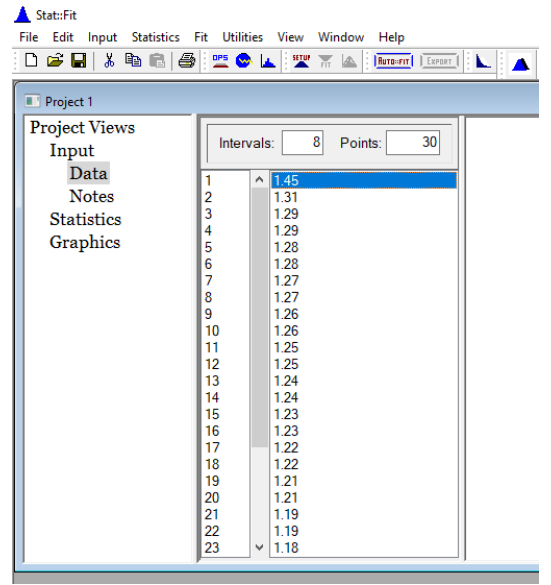

Gambar 3. Data Waktu Pengiriman Kue Ali (Ledram)

- Klik perintah Auto::Fit, Klik p atau dengan memilih menu : Fit - Auto::Fit.

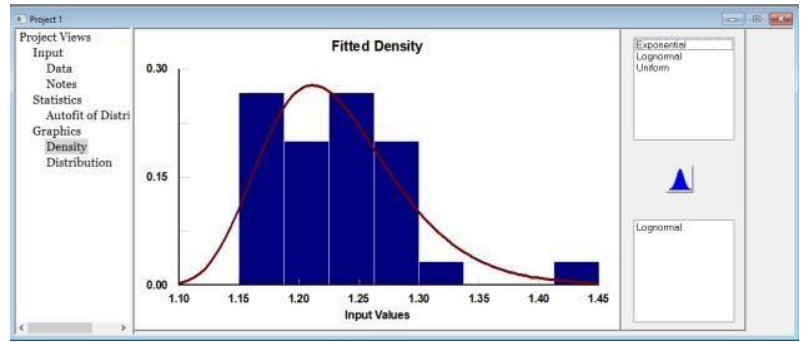

Gambar 4. Comparison Graph

- Pilih distribusi dengan rangking paling tinggi sehingga akan keluar angka yang nantinya akan digunakan pada ProModel.

- Sebelum hasil distribusi digunakan, maka terlebih dahulu diexport, caranya klik atau klik File-Export-Export Fit, sehingga akan tampil dialog box dan klik Clipboard.

b. Membuat File Baru

c. Membuat Locations

- Pilih menu Buil - Locations dan Akan terbuka jendela lokasi.

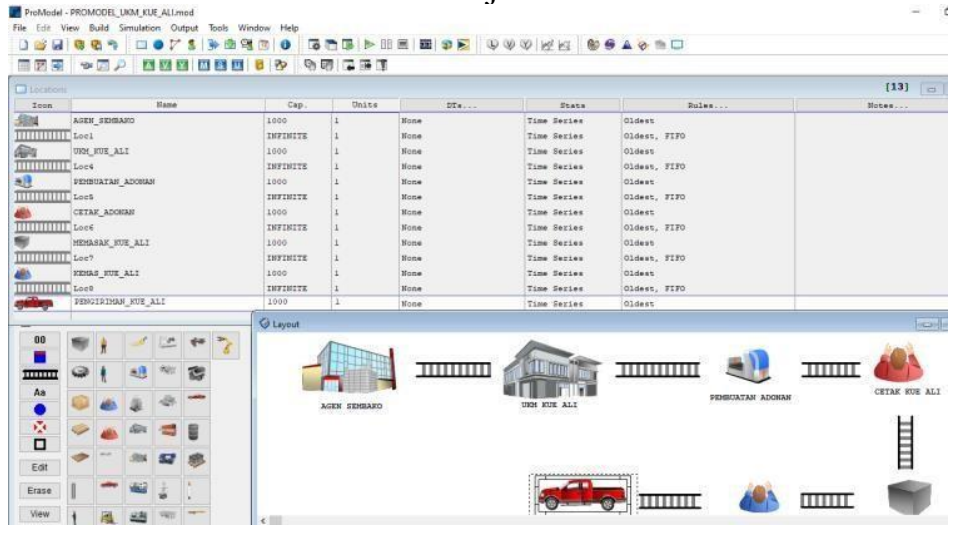

Gambar 5. Menu Buil - Locations Software ProModel

- Dari tabel Graphic pilih simbol yang melambangkan lokasi kemudian klik pada Lay Out isi Locations Table (Name, Cap., etc) 
- Pemberian nama lokasi pada lay out: uncheck "New" pada Graphics klik icon

- Pembuatan conveyor

Klik pada Graphics klik pada lay out (Akan muncul panah double klik untuk mengakhiri. Kemudian mendefinisikan panjang dan kecepatan pada conveyor options diisi "length" dan "speed" conveyor sesuai studi kasus (UKM Kue Ali (Ledram) Pak beben).

\section{d. Menentukan Entitas}

- Pilih menu Buil - Entities

- Dari tabel Entity Graphic pilih salah satu symbol

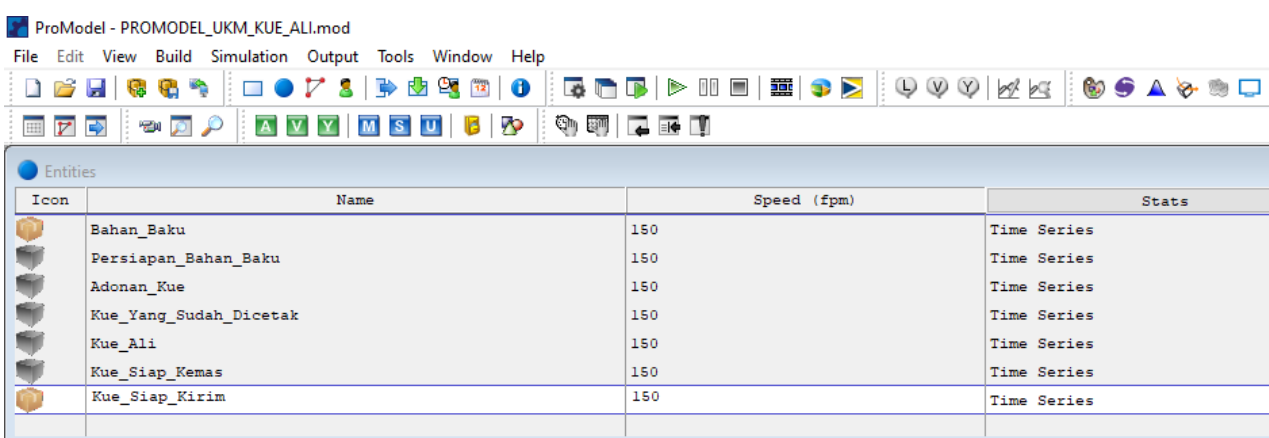

\section{Gambar 6. Menu Buil - Entities Software Promodel}

- Pada tabel entities tidak ada perubahan pada kolom Name, Speed, Stats, dan Notes.

\section{e. Mendefinisikan Processing}

- Pilih menu Buil - Processing

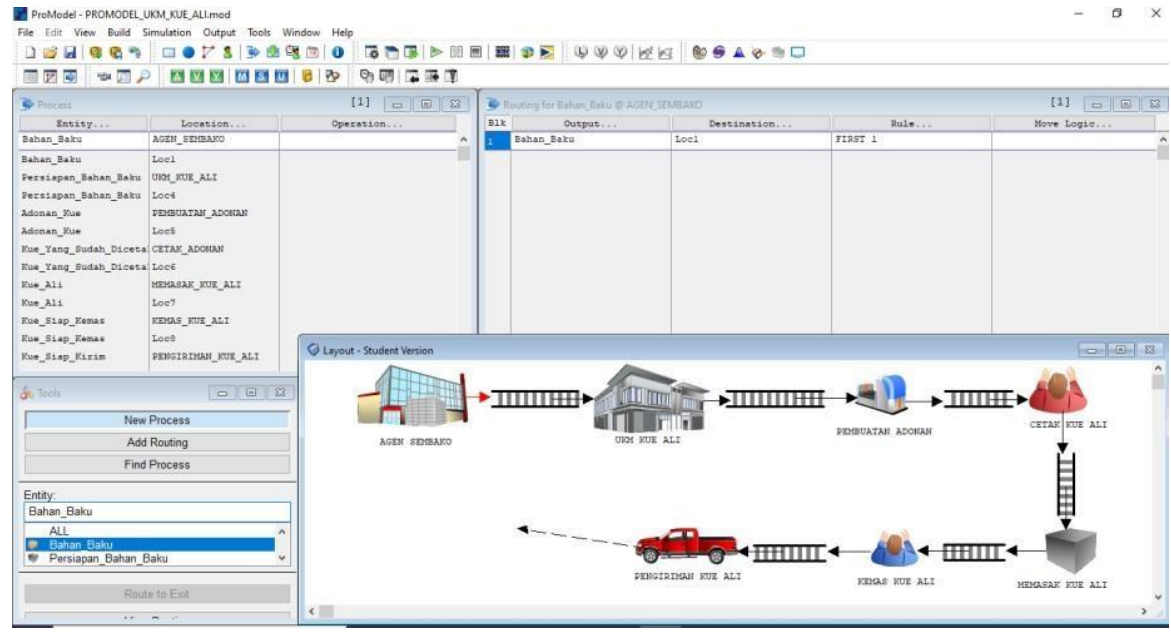

Gambar 7. Menu Buil - Processing Software Promodel

\section{f. Mendefinisikan Arrivals}

- Pilih menu Buil - Arrivals 


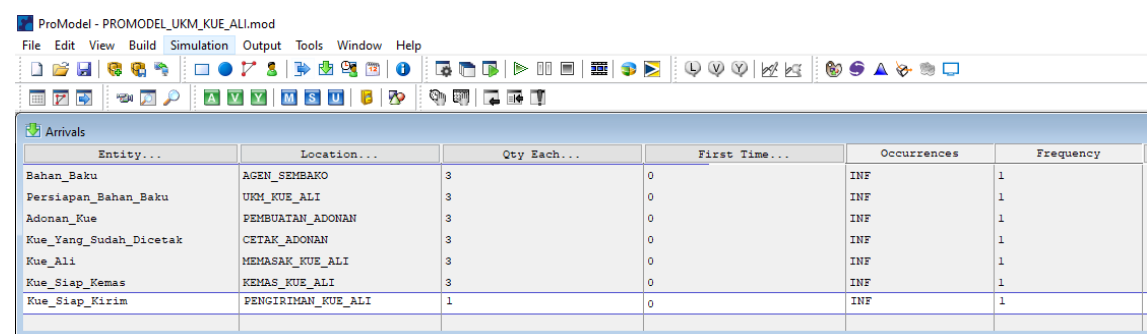

Gambar 8. Menu Buil - Arrivals Software Promodel

\section{g. Mendefinisikan waktu Running Simulasi}

- Pilih menu Simulation pilih Option

- Set run hours pada 12 kemudian Run simulasi

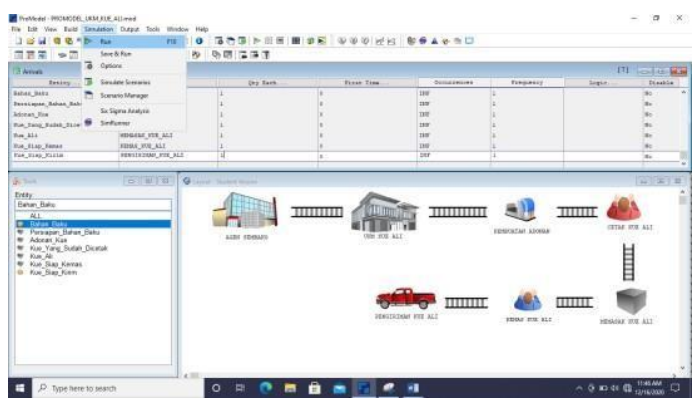

Gambar 9. Menu Simulations - Run Software Promodel

\section{Tampilan Simulasi Sistem Pada Software Promodel}

Apabila data-data diatas sudah dimasukkan, maka Akan tampak visualisasi sistem pada UKM Kue Ali (ledram) Pak Beben yaitu sebagai berikut:

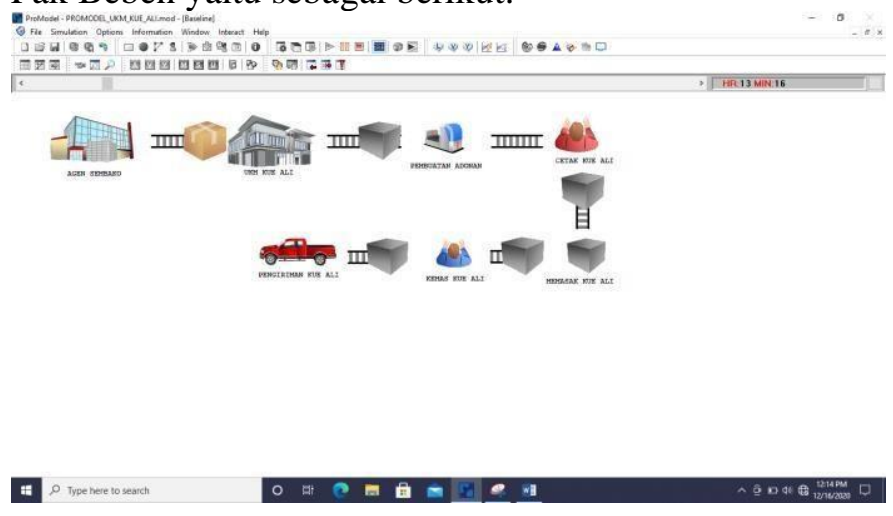

\section{Gambar 10. Run Simulasi Sistem Pada Software Promodel}

\section{Output}

Dari aliran proses produksi tersebut, diatur waktu kerja selama 8 jam, yang mana sebagai perumpamaan jam kerja pada waktu sesungguhnya. Setelah itu simulasi diagram aliran proses produksi tersebut mulai dijalankan.

Dengan menggunakan ProModel, dapat diketahui tingkat produksi yang dihasilkan dari simulasi yang dibuat. Data yang dihasilkan berupa grafik statistik masing-masing stasiun kerja, yang mana juga bisa mengetahui apa saja proses yang sedang berjalan, in proses dan kegagalan produk yang dihasilkan.

Untuk melihat hasil output dari model yang telah dikerjakan, dapat dilihat pada menu bar kemudian pilih output, lalu view statistics, maka akan tampil seperti Gambar 11- berikut. 


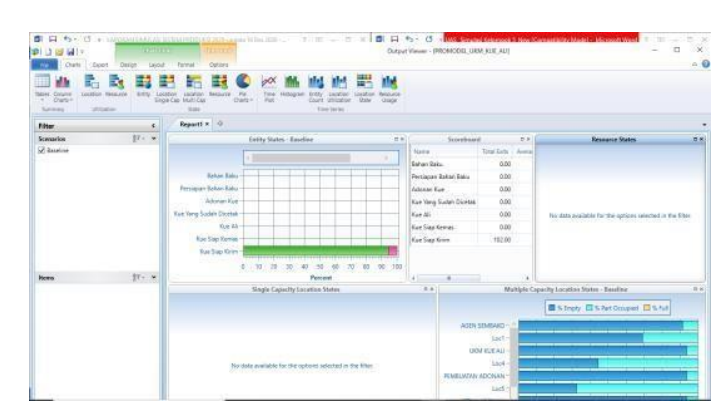

Gambar 11. Statistik Data Hasil Simulasi

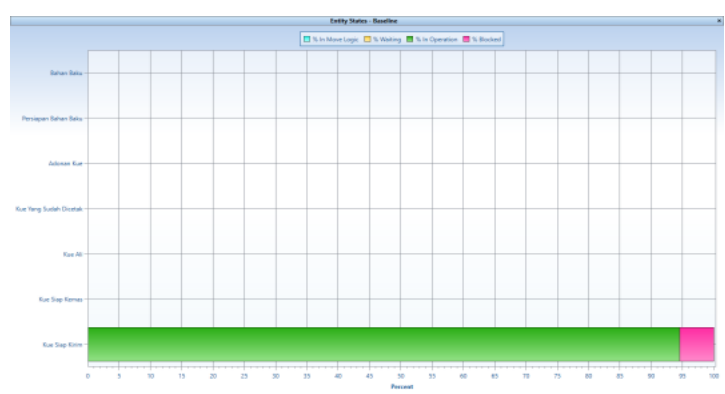

Gambar 12. Data Entitas

\begin{tabular}{|l|r|r|r|r|r|}
\hline Name & Total Exits & Average Time In System (Min) & $\begin{array}{l}\text { Average Time In } \\
\text { Operation (Min) }\end{array}$ & Average Cost & \\
\hline Bahan Baku & 0.00 & 0.00 & 0.00 & 0.00 \\
\hline Persiapan Bahan Baku & 0.00 & 0.00 & 0.00 & 0.00 \\
\hline Adonan Kue & 0.00 & 0.00 & 0.00 & 0.00 \\
\hline Kue Yang Sudah Dicetak & 0.00 & 0.00 & 0.00 & 0.00 \\
\hline Kue Ali & 0.00 & 0.00 & 0.00 & 0.00 \\
\hline Kue Siap Kemas & 0.00 & 0.00 & 0.00 & 0.00 \\
\hline Kue Siap Kirim & 44.00 & 0.52 & 0.49 & 0.00 \\
\hline
\end{tabular}

\section{Gambar 13. Data Hasil Produksi}

Berdasarkan hasil simulasi menggunakan Promodel, didapatkan hasil yang cukup bagus, namun masih terjadi kegagalan produk yang cukup besar pada entitas kue siap kirim sebesar $5.23 \%$. Hal ini disebabkan karena pencapaian pengiriman kue Ali (ledram) pada stasiun kue siap kirim yang rendah. Dapat kita lihat pada hasil scoreboard ProModel produk kue siap kirim yang dihasilkan hanya sebanyak total exits kue siap kirim yakni $44 \mathrm{pcs} /$ customer. Average time in system sebesar 0.52 , average time in operation sebesar 0.49 . Rendahnya pencapaian pengiriman siap kirim dikarenakan pada Arrivals Qty Each/man power nya rendah yaitu 1 orang.

\section{Skenario Perbaikan (Improvement) Sistem Eksisting}

Hasil dari simulasi sistem eksisting menunjukkan bahwa pencapaian pengiriman yang masih rendah karena tidak balance antara Arrivals Qty Each/man power yang lain terhadap kemampuan pengiriman. Dari kondisi tersebut, kemudian diusulkan skenario perbaikan (improvement) dengan menambah man power pada proses kue siap kirim. Dengan menambah man power berarti akan meningkatkan kapasitas pengiriman kue.

Setelah dilakukan improvement, dapat dilihat hasil statistik aliran proses pengiriman kue Ali (ledram) seperti yang terlihat pada Gambar 14 berikut: 
Dapat dilihat pada hasil scoreboard ProModel sebelum di-improve, produk kue siap kirim yang sebelumnya dihasilkan hanya sebanyak $44 \mathrm{pcs} /$ customer, average time in system sebesar 0.52 , average time in operation sebesar 0,49 .

Setelah dilakukan improvement, yaitu dengan menambah man power sebanyak 3 orang di masing-masing station, total exits kue siap kirim naik menjadi 68 pcs/customer, average time in sistem sebesar 0.48 (waktu lebih rendah), average time in operation sebesar 0.45 (waktu lebih rendah).

\section{KESIMPULAN}

Berdasarkan hasil pengamatan dan pembuatan model simulasi yang dilakukan terhadap UKM kue Ali (ledram) Pak Beben, didapat kesimpulan bahwa pada sistem produksi kue Ali (ledram) masih kekurangan tenaga kerja untuk proses produksinya. Hal ini menyebabkan tingkat kegagalan pengiriman kue siap kirim masih ada. Setelah dilakukan improvement, terlihat bahwa hasil simulasi tidak menunjukkan adanya kegagalan pengiriman pada aliran proses pengiriman kue. Proses transfer kue siap kemas ke kue siap kirim juga lancar tidak terjadi penumpukan atau over kapasitas. Sehingga dapat disimpulkan bahwa improvement yang dilakukan sudah efektif dengan menambah man power sehingga menambah kapasitas pengiriman kue Ali (ledram).

\section{DAFTAR PUSTAKA}

Dinas Perhubungan Kabupaten Karawang. (2018). “Ali Agrem Khas Karawang”. Karawang.

Siregar, K. (2017). "Simulasi dan Pemodelan (Aplikasi untuk Keteknikan Pertanian)". Aceh: Dee Publish. 